\title{
PAPER
}

\section{Neuromuscular and sensory disturbances in patients with well treated coeliac disease}

\author{
L Luostarinen, S-L Himanen, M Luostarinen, P Collin, T Pirttilä
}

J Neurol Neurosurg Psychiatry 2003;74:490-494

See end of article for authors' affiliations

......................

Correspondence to: Dr L Luostarinen,

Department of Neurology,

Päijät-Häme Central

Hospital,

Keskussairaalankatu 7, FIN

-15850 Lahti, Finland;

liisa.luostarinen@phks.fi,

Received 26 July 2002

Accepted in revised form

21 December 2002

\begin{abstract}
Objectives: A body of evidence shows that coeliac disease is associated with protean manifestations outside the intestine, and neurological disorders are well recognised. However, it remains obscure whether there are signs of clinical or subclinical nervous system involvement even in patients adopting an adequate gluten free diet. The aim of this study was to assess in a controlled study whether patients with treated coeliac disease carry an increased risk for neuropathy and characterise the type of possible neuropathy.

Methods: Electroneuromyographic findings and vibration, thermal, and tactile thresholds of 26 patients with coeliac disease and 23 patients with reflux disease were analysed.

Results: Six $(23.1 \%)$ coeliac disease patients and one $(4.3 \%)$ reflux disease patient showed findings of chronic axonal neuropathy in quantitative needle EMG. In addition, two coeliac disease patients showed findings suggestive for myopathy. There were no significant differences in warm, cold, or vibration thresholds between the groups but means of heat pain thresholds and tactile thresholds were significantly higher in coeliac patients than in controls.

Conclusion: An increased occurrence of axonal neuropathy was observed in well treated coeliac disease. This further indicates that neurological manifestations occur even in patients without overt malaborption.
\end{abstract}

C oeliac disease is an inflammatory condition of the small intestine characterised by villous atrophy and crypt hyperplasia induced by dietary gluten in genetically susceptible people, possibly affecting 1:300-1:100 of the population. The most common symptoms are diarrhoea, weight loss, and malabsorption, which recover with a gluten free diet. Coeliac disease may remain silent, but it can lead to various non-gastrointestinal complications such as osteoporosis, infertility, or lymphoma. Gluten free diet is beneficial in preventing these complications, and the risk seems to be altogether low in treated patients. The diagnosis is established by the finding of small bowel villous atrophy and clinical or histological remission on gluten free diet. ${ }^{1}$ Untreated coeliac disease may present with various neurological manifestations such as cerebellar ataxia, epilepsy, or brain atrophy. ${ }^{2-6}$ Association between peripheral neuropathy and coeliac disease has been described, ${ }^{7-9}$ and recently, Hadjivassiliou with his colleagues reported nine patients in whom neuromuscular disorder was a presenting feature of coeliac disease. ${ }^{9}$ Diabetes and alcohol misuse are the most common causes of peripheral neuropathy in developed countries. Other well established causes of neuropathy include hereditary, metabolic, toxic, infectious, inflammatory, ischaemic, and paraneoplastic disorders. However, despite extensive evaluation, the aetiology remains unknown in up to $20 \%$ of patients with neuropathy even in very specialised neurological units. ${ }^{111}$

The role of gluten free diet has remained unknown in modifying symptoms and findings of neuropathy in coeliac disease. Gluten free diet may reverse or at least slow down the progression of peripheral neuropathy and on the other hand, transgressions in gluten free diet may exacerbate neurological disorders in coeliac disease. In one case report the symptoms disappeared after introducing gluten free diet. ${ }^{8}$

The aim of this cross sectional study was to assess whether even patients with a well treated coeliac disease carry an increased risk of neuropathy.

\section{METHODS}

The study was carried out at the Department of Neurology in Tampere University Hospital. The study group comprised 26 patients with coeliac disease. The diagnosis of coeliac disease had been established according to current criteria of European Society for Paediatric Gastroenterology and Nutrition ${ }^{12}$ at the department of Medicine in Tampere University Hospital. All coeliac disease patients were maintaining gluten free diet since the establishment of the diagnosis for a median of three years (range 2-28). They were in clinical and histological remission-that is, they had no small bowel mucosal atrophy anymore. Control biopsies were no older than three years before neurophysiological studies and the strictness of gluten free diet was assessed by interview. Twenty three patients with gastro-oesophageal reflux disease served as controls; coeliac disease was excluded by histological examination of small bowel mucosa while these patients were evaluated for surgical treatment for gastro-oesophageal reflux disease (table 1).

The study protocol was approved by the ethical committee of Tampere University Hospital, and written informed consent was obtained from all patients.

Neurophysiological examinations included the measures of the function of both motor fibres and sensory large fibres and small myelinated and unmyelinated fibres.

Electroneuromyography (ENMG) was carried out using a Keypoint (Dantec, Skovlunde, Denmark) ENMG device. As a rule, the ENMG was performed to the left extremities. In addition, the right extremities were examined in patients with predominantly right sided symptoms. Concentric needle electromyography (EMG) was performed on one distal ( $m$ tibialis anterior) and one proximal (m biceps brachii) muscle. The EMG was considered abnormal if fibrillation or positive sharp waves, or both were present in more than one location within

Abbreviations: ENMG, electroneuromyography; EMG electromyography; MUP, motor unit potential 


\section{Table 1 Demographic data}

\begin{tabular}{lll}
\hline & $\begin{array}{l}\text { Coeliac } \\
\text { disease } \\
\text { patients }\end{array}$ & $\begin{array}{l}\text { Reflux } \\
\text { disease } \\
\text { patients }\end{array}$ \\
\hline Number of patients (male/female) & $26(7 / 19)$ & $23(16 / 7)$ \\
Mean age (range) (y) & $51(22-77)$ & $50(18-73)$ \\
Time from diagnosis: mean (range) (y) & $4(2-28)$ & $4(0-31)$ \\
Time from diagnosis: median (y) & 3 & 3 \\
Predisposing factor to neuropathy & $7(27 \%)^{*}$ & $5(22 \%)^{*}$ \\
\hline${ }^{*} \mathrm{p}=$ NS. & & \\
\hline
\end{tabular}

the muscle. In addition, the muscles were studied quantitatively by the multi-mup analysis method. ${ }^{13}$ The number of outliers $^{14}$ were noticed as well as the mean amplitude and duration of the motor unit potentials (MUPs), which were compared with reference values provided by the manufacturer. ${ }^{15}$ The results were considered abnormal if the number of outliers exceeded three, or the mean values were outside the normal range ( $>2.5 \mathrm{SD}$ ). Nerve conduction studies were carried out in motor nerves (left median, ulnar, and peroneal nerves) and sensory nerves (left median, ulnar, radial, and sural nerves). All studies were performed with surface electrodes using standard techniques ${ }^{16}{ }^{17}$ with the exception of the median and ulnar digital nerves, which were measured antidromically. The hands and feet were warmed at least up to $30^{\circ} \mathrm{C}$ before all conduction velocity measurements.
The left peroneal motor conduction measurements, the left sural and radial sensory measurements, and $\mathrm{F}$ waves of all motor nerves were utilised. The results were compared with reference values provided by the manufacturer standardised for age and height. The conduction velocities were considered abnormal if they were slower than 2.5 SD from the calculated mean.

Vibration thresholds were measured from carpal and tarsal areas using the method of limits (Vibrameter, Somedic, Stockholm, Sweden). In addition, vibration thresholds from the index fingers and big toes were studied by the BioThesiometer (Bio Medical Instrument, Newbury, OH, USA). Thermal thresholds (heat, cold, and heat pain thresholds) were assessed by a skilled technician by Somedic Thermotest equipment (Somedic) as previously described.$^{18}$ Tactile thresholds were assessed with Semmes-Weinstein monofilaments ${ }^{19}$ in dermatomes L3 and S1.

\section{Statistical methods}

Data were expressed as means with standard deviations or frequencies as indicated. Confidence intervals (95\%) and contingency table with $\chi^{2}$ test and Mann-Whitney $U$ test were used for statistical comparisons when appropriate.

\section{RESULTS}

\section{Clinical examination}

Nine coeliac disease patients and 11 patients with reflux disease complained of numbness and paraestesias distally in the

Table 2 Clinical data and neurophysiological findings in seven patients with neuropathy

\begin{tabular}{|c|c|c|c|c|c|c|c|}
\hline & 1 & 2 & 3 & 4 & 5 & 6 & 7 \\
\hline Disease & Coeliac disease & Coeliac disease & Coeliac disease & Coeliac disease & Coeliac disease & Coeliac disease & Reflux disease \\
\hline Time from diagnosis (y) & 3 & 2 & 3 & 4 & 2 & 3 & 6 \\
\hline Sex & male & female & female & female & female & male & male \\
\hline Age & 70 & 56 & 77 & 65 & 60 & 67 & 54 \\
\hline Possible predisposing factor & no & no & no & no & Graves' disease & alcohol & no \\
\hline Clinical/subclinical neuropathy & clinical & clinical & subclinical & subclinical & subclinical & clinical & clinical \\
\hline \multicolumn{8}{|c|}{ Motor nerve conduction } \\
\hline \multicolumn{8}{|l|}{ Median nerve (elbow-wrist) } \\
\hline Amplitude (mV) & 3.4 & 2.1 & 3.3 & 8.2 & 3.9 & 3.4 & 3.7 \\
\hline Velocity $(\mathrm{m} / \mathrm{s})$ & 54 & 53 & 49 & 54 & 64 & 52 & 56 \\
\hline \multicolumn{8}{|l|}{ Ulnar nerve (elbow-wrist) } \\
\hline Amplitude $(\mathrm{mV})$ & 8.3 & 6.2 & 7.5 & 8.6 & 11 & 6.9 & 6.5 \\
\hline Velocity $(\mathrm{m} / \mathrm{s})$ & 55 & 66 & 63 & 64 & 66 & 49 & 64 \\
\hline \multicolumn{8}{|c|}{ Peroneal nerve (knee-ankle) } \\
\hline Amplitude (mV) & 3.2 & 3.2 & 3.2 & 4.6 & 4.5 & 6.6 & 8.2 \\
\hline Velocity $(\mathrm{m} / \mathrm{s})$ & 37 & 42 & 44 & 48 & 46 & 42 & 46 \\
\hline \multirow{2}{*}{\multicolumn{8}{|c|}{$\begin{array}{l}\text { Sensory nerve conduction } \\
\text { Median nerve (wrist-digit 2) }\end{array}$}} \\
\hline & & & & & & & \\
\hline Amplitude $(\mu \mathrm{V})$ & 6.1 & 45 & 4.8 & 38 & 28 & 8.5 & 24 \\
\hline Velocity $(\mathrm{m} / \mathrm{s})$ & 54 & 56 & 48 & 58 & 67 & 50 & 58 \\
\hline \multicolumn{8}{|l|}{ Ulnar nerve (wrist-digit 5) } \\
\hline Amplitude $(\mu \mathrm{V})$ & 3.5 & 21 & 5.8 & 31 & 23 & 11 & 19 \\
\hline Velocity $(\mathrm{m} / \mathrm{s})$ & 59 & 54 & 40 & 58 & 54 & 56 & 61 \\
\hline \multicolumn{8}{|l|}{ Sural nerve (calf-ankle) } \\
\hline Amplitude $(\mu \mathrm{V})$ & 2.7 & 4.4 & 7.3 & 4.7 & 8.2 & 12 & 4.4 \\
\hline Velocity $(\mathrm{m} / \mathrm{s})$ & 48 & 54 & 45 & 47 & 54 & 42 & 64 \\
\hline \multirow{2}{*}{\multicolumn{8}{|c|}{$\begin{array}{l}\text { EMG findings } \\
\mathrm{m} \text { tibialis anterior }\end{array}$}} \\
\hline & & & & & & & \\
\hline mean amplitude (SD) & $4^{*}$ & 1.5 & 1.2 & 1.6 & 0.2 & 1.1 & 1.3 \\
\hline duration of MUPs (SD) & $3.6 *$ & $2.5^{*}$ & $2.9 *$ & $3.9 *$ & $3.4^{*}$ & 0 & 2 \\
\hline $\begin{array}{l}\text { Number of outliers } \\
\mathrm{m} \text { biceps brachii }\end{array}$ & $\mathrm{A} 9 *, \mathrm{D} 3$ * & $\mathrm{Al}, \mathrm{D}^{*}$ * & $\mathrm{Al}, \mathrm{D} 7^{*}$ & $\mathrm{~A} 2, \mathrm{D} 3{ }^{*}$ & $\mathrm{AO}, \mathrm{Dl}$ & $\mathrm{AO}, \mathrm{DOl}$ & $\mathrm{A} 3^{*}, \mathrm{D} 2$ \\
\hline mean amplitude (SD) & 0.3 & 2.3 & 1.8 & 0.6 & 0 & $2.7^{*}$ & 0.6 \\
\hline duration of MUPs (SD) & 0.2 & 1.8 & -0.7 & 1.2 & 1.5 & 0.1 & 0 \\
\hline Number of outliers & $\mathrm{A} 0, \mathrm{D} 1$ & $\mathrm{AO}, \mathrm{DO}$ & $\mathrm{Al}$, DO & $\mathrm{AO}, \mathrm{DI}$ & $\mathrm{AO}, \mathrm{D} 5^{*}$ & $\mathrm{AO}, \mathrm{DO}$ & $\mathrm{A} 0, \mathrm{D} 2$ \\
\hline \multicolumn{8}{|l|}{ Heat pain threshold $\left({ }^{\circ} \mathrm{C}\right)$} \\
\hline Left thenar & 54.4 & 47.1 & 44.7 & 50.5 & 49.4 & 48.1 & 49.2 \\
\hline Left foot & 49.4 & 48.3 & 47.3 & 47.0 & 47.5 & 46.6 & 45.3 \\
\hline \multicolumn{8}{|c|}{$\begin{array}{l}\text { Tactile threshold ( as } 10 \text { log of force, mg compressing skin) } \\
\text { Left leg }\end{array}$} \\
\hline Dermatome L3 & 3.84 & $4.74^{*}$ & $5.07^{*}$ & 3.84 & 4.08 & 4.17 & 2.44 \\
\hline Dermatome S1 & 3.84 & 4.56 & 4.31 & 4.08 & 4.08 & 4.08 & 4.56 \\
\hline
\end{tabular}




\begin{tabular}{|c|c|c|c|}
\hline & $\begin{array}{l}\text { Coeliac disease patients } \\
\mathrm{n}=26 \text { mean (SD) }\end{array}$ & $\begin{array}{l}\text { Reflux disease patients } \\
\mathrm{n}=23 \text { mean (SD) }\end{array}$ & $\mathrm{p}$ \\
\hline \multicolumn{4}{|l|}{ Warm threshold $\left({ }^{\circ} \mathrm{C}\right)$} \\
\hline Left thenar & $1.7(0.8)$ & $1.7(1.0)$ & 0.8895 \\
\hline Left foot & $5.1(3.4)$ & $6.0(3.4)$ & 0.3760 \\
\hline \multicolumn{4}{|l|}{ Cold threshold $\left({ }^{\circ} \mathrm{C}\right)$} \\
\hline Left thenar & $1.0(0.3)$ & $0.9(0.3)$ & 0.3269 \\
\hline Left foot & $1.3(0.8)$ & $1.8(1.8)$ & 0.2573 \\
\hline \multicolumn{4}{|c|}{ Heat pain threshold $\left({ }^{\circ} \mathrm{C}\right)$} \\
\hline Left thenar & $46.9(4.5)$ & $44.5(3.5)$ & 0.0454 \\
\hline Left foot & $46.1(2.9)$ & $42.9(3.2)$ & 0.0005 \\
\hline \multicolumn{4}{|l|}{$\begin{array}{l}\text { Vibration threshold } \\
\text { (deviation from mean) }\end{array}$} \\
\hline Left wrist & $0.3(0.2)$ & $0.4(0.2)$ & 0.4451 \\
\hline Left ankle & $2.9(8.8)$ & $1.7(1.5)$ & 0.5889 \\
\hline \multirow{2}{*}{\multicolumn{4}{|c|}{$\begin{array}{l}\text { Tactile threshold ( as } 10 \text { log of force, mg, compressing skin) } \\
\text { Left leg }\end{array}$}} \\
\hline Left leg & & & \\
\hline Dermatome L3 & $3.9(0.7)$ & $2.1(0.7)$ & $<0.001$ \\
\hline Dermatome S1 & $4.1(0.7)$ & $2.9(0.8)$ & $<0.001$ \\
\hline
\end{tabular}

extremities. Objective clinical signs of polyneuropathy (absent tendon reflexes and diminished sensory findings) were found in three coeliac disease patients. Seven (27\%) coeliac disease patients and five $(22 \%)$ control patients had a possible predisposing factor to neuropathy (table 1); the difference was not statistically significant. Altogether four patients suffered from alcoholism, one had operated breast cancer, two had medically treated hypothyroidism, and two had treated Graves' disease, one suffered from inactive ankylosing spondylitis and two had treated rheumatoid arthritis. No patients had previous diagnosis of diabetes, vitamin deficiency, or malnutrition.

\section{ENMG findings}

Altogether six $(23.1 \%$, three with clinically symptomatic and three asymptomatic neuropathy) coeliac disease patients and one $(4.3 \%)$ reflux disease patient revealed findings of chronic axonal motor neuropathy in quantitative EMG with increased amplitude or duration of the MUPs. The findings were more prominent in distal than proximal muscles in five of six coeliac disease patients. None of the subjects had fibrillations or positive sharp waves in EMG. The clinical data and results of patients with neuropathy are summarised in table 2 . All conduction velocities and amplitudes of the action potentials as well as F latencies were within reference values in each coeliac and control patient. In neuropathy patients sensory and motor action potential amplitudes tended to be lower. Thus three coeliac disease patients had clinically symptomatic and three had subclinical, mainly distal chronic axonal neuropathy, whereas only one control patient had subclinical axonal neuropathy. Reasons of subjective numbness and paraestesias in the rest of the patients remained unclear. Two of the six coeliac patients with neuropathy had a predisposing factor for neuropathy (table 2). Four $(21.1 \%)$ of 19 coeliac disease patients without predisposing factor compared with one $(5.6 \%)$ out 18 controls had neuropathy findings $(\mathrm{p}=0.3)$.

Two coeliac disease patients $(7.7 \%)$ showed reduced amplitudes and duration of MUPs in quantitative EMG. Muscle biopsy was not performed because the patients did not show clinical signs of myopathy.

\section{Quantitative somatosensory findings}

Heat pain and tactile thresholds in both upper and lower extremities were significantly higher in patients with coeliac disease than in control subjects. There were no significant differences in warm, cold, or vibration thresholds between the groups (table 3 ). When patients with neuropathy were excluded, mean values of tactile thresholds in both upper and lower extremities and heat pain thresholds in lower extremity were significantly higher in patients with coeliac disease than in control subjects (table 4). All patients with neuropathy finding in ENMG, that is six with coeliac disease and one with reflux disease had higher means of somatosensory thresholds than patients without neuropathy. We could not demonstrate any patient with pure small fibre neuropathy.

\section{DISCUSSION}

Our study is the largest comparative study assessing the frequency and features of neuromuscular disorders associated with coeliac disease. We showed that even well treated patients with coeliac disease carry an increased risk of neuropathy, to be seen in one fourth $(23 \%)$ of patients. Even more, $31 \%$, showed abnormalities in neurophysiological studies compared with $4.3 \%$ in controls. Although most manifestations were subclinical, coeliac disease can be considered as a

\begin{tabular}{|c|c|c|c|}
\hline & $\begin{array}{l}\text { Coeliac disease patients } \\
\mathrm{n}=20 \text { mean (SD) }\end{array}$ & $\begin{array}{l}\text { Reflux disease patients } \\
\mathrm{n}=22 \text { mean (SD) }\end{array}$ & $\mathrm{p}$ \\
\hline \multicolumn{4}{|c|}{ Heat pain threshold $\left({ }^{\circ} \mathrm{C}\right)$} \\
\hline Left thenar & $46.3(4,7)$ & $44.2(3.4)$ & 0.13 \\
\hline Left foot & $45.7(3.1)$ & $42.8(3.2)$ & 0.0049 \\
\hline \multicolumn{4}{|c|}{$\begin{array}{l}\text { Tactile threshold (as } 1 \text { Olog of force, mg, compressing skin) } \\
\text { Left leg }\end{array}$} \\
\hline Dermatome L3 & $3.86(0.64)$ & $2.21(0.73)$ & $<0.001$ \\
\hline Dermatome S1 & $4.04(0.78)$ & $2.92(0.74)$ & $<0.001$ \\
\hline
\end{tabular}


risk condition for neuromuscular disorders. In fact, neuropathy in coeliac disease is as common in coeliac disease as in diseases commonly thought to be risk factors for neuropathy. By comparison, in scleroderma, the frequency of neuropathy has been reported to be $34 \%$, clinical neuropathy in $15.6 \%$, and subclinical in $18.8 \%{ }^{20}$ In patients with newly diagnosed noninsulin dependent diabetes $8.3 \%$ had definite or probable polyneuropathy compared with $2.1 \%$ among the control subjects; a frequency comparable to our control group. ${ }^{21}$ Seven patients in the coeliac group and five in the control group had a predisposing factor for neuropathy, of these two coeliac patients had neuropathy (table 2). We cannot exclude that these predisposing conditions might be aetiological factors for neuropathy. However, when people without known predisposing factors for neuropathy were excluded, the frequency of neuropathy was higher $(21.1 \%)$ in coeliac disease patients than in controls $(5.6 \%)$. Even though the difference was not statistically significant, the finding suggests that coeliac disease itself may carry an increased risk of neuropathy. On the other hand it may also be that coeliac disease may aggravate neuropathy when there already exists some underlying risk for this complication.

Most studies of neurological complications of coeliac disease have emphasised central nervous system involvement. Association of neuropathy or myopathy with coeliac disease has been described infrequently over time. Holmes ${ }^{22}$ has analysed neurological manifestations in a community based coeliac disease population $(n=388)$. In this study the frequency of neuropathy was $0.5 \%$ and for myopathy $1.3 \%$. In all cases, myopathy was a result of osteomalacia, which is nowadays very uncommon in coeliac disease and responded to treatment with vitamin D and gluten free diet. There are no previous controlled studies with neurophysiological measurements concerning the frequency of neuropathy in association with coeliac disease. Kaplan et al $^{8}$ described a middle aged man with 15 year history of coeliac disease who developed a large fibre axonopathy affecting mainly sensory fibres. Sural nerve biopsy demonstrated Wallerian degeneration and findings indicating degeneration and regeneration of nerve fibres. One recent study showed inflammatory cell infiltrates in the nerve roots of the spinal cord in a coeliac patient with polyneuropathy. ${ }^{23}$ The largest series until now was reported by Hadjivassiliou et al. ${ }^{9}$ They described six patients with axonal sensorimotor polyneuropathy (of whom two presented with a pure motor neuropathy), one patient with mononeuropathy multiplex and one patient with Guillan-Barre type acute polyneuropathy affected by coeliac disease. Sensory deficits were more pronounced than motor findings in six patients with axonal polyneuropathy. Our results verify that polyneuropathy associated with coeliac disease is axonal type and affects both motor and sensory fibres. We also showed for the first time that patients with coeliac disease showed higher heat pain and touch thresholds than controls. This finding still existed when patients with neuropathy diagnosis were excluded from analysis. Increase of heat pain and touch thresholds in coeliac patients compared with controls provide further evidence that peripheral nerve fibres, even small unmyelinated fibres, are affected in coeliac patients.

Even though all our patients were adopting gluten free diet and coeliac disease was in good remission, they still had an increased risk of clinical or subclinical neuropathy. Earlier, patients with coeliac disease were often malnourished and suffered from severe malabsorption of nutrients. Only the most severe cases were detected, and manifest neurological complications occurred in as many as $36 \%$ of patients. ${ }^{24}$ Influence of gluten free diet in the alleviation of the neuropathy is poorly understood. However, polyneuropathy has been reported to resolve after gluten withdrawal in coeliac disease. ${ }^{8}$ All patients with neuropathy findings were 54 years or older and there may have been long diagnostic delay before introducing gluten free diet. It is therefore not excluded that gluten free diet may have prevented the development of symptomatic neuropathy in some of our patients. Because $23 \%$ of our patients on a gluten free diet had still signs of neuropathy, alternative mechanisms, apart from gluten, may be involved in the development of neuropathy.

One possibility for the occurrence of neurological complications in coeliac disease is an immune reaction against a shared epitope expressed in small intestine and peripheral nerve or muscle. Coeliac disease is an inflammatory disorder induced by dietary gluten. Immunological and genetic factors contribute to the pathogenesis of the disease. The genetic susceptibility locus is in the MHC region, and the disease is associated with the HLA-DQ alleles DQAl*0501 and DQB1*0201. A recent study by Hadjivassiliou et $a l^{4}$ has shown the high HLA-DQ 2 association with sporadic ataxia attributable to gluten sensitivity and subsequently confirmed by Burk et al..$^{25}$ It is probable that immunological factors contribute to the development of neuropathy in coeliac disease.

In conclusion, coeliac patients have an increased frequency of chronic axonal neuropathy, even when adhering to a long term strict gluten free diet. Early detection of coeliac disease might prevent the development of manifest neuropathy. The relation between gluten containing diet and the occurrence of neuropathy is a subject for further studies. Until that, it is reasonable to assume that a strict diet is warranted to prevent manifest neuropathy and follow up of dietary compliance would be indicated.

\section{Authors' affiliations}

L Luostarinen, Departments of Neurology, Tampere University Hospital and Medical School, University of Tampere, and Päijät-Häme Central Hospital, Lahti, Finland

S-L Himanen, Department of Clinical Neurophysiology, Tampere University Hospital and Medical School

M Luostarinen, Department of Surgery, Tampere University Hospital and Medical School, University of Tampere, and Päijät-Häme Central Hospital P Collin, Department of Internal Medicine, Tampere University Hospital and Medical School

T Pirttilä, Departments of Neurology, University of Tampere, University of Kuopio and Kuopio University Hospital, Kuopio, Finland

Funding: this work was supported by a grant from the Medical Research Fund of Tampere University Hospital.

Competing interests: none declared.

\section{REFERENCES}

1 Mäki M, Collin P. Coeliac disease. Lancet 1997;349:1755-9.

2 Cronin CC, Jackson LM, Feighery $C$, et al. Coeliac disease and epilepsy. Q J Med 1998;91:303-8.

3 Hadjivassiliou M, Gibson A, Davies-Jones GA, et al. Does cryptic gluten sensitivity play a part in neurological illness? Lancet 1996;347:369-71.

4 Hadiivassiliou M, Grunewald RA, Chattopadhyay AK, et al. Clinical, radiological, neurophysiological, and neuropathological characteristics of gluten ataxia. Lancet 1998;352:1582-5.

5 Pellecchia MT, Scala R, Filla A, et al. Idiopathic cerebellar ataxia associated with celiac disease: lack of distinctive neurological features. $J$ Neurol Neurosurg Psychiatry 1999;66:32-5.

6 Collin P, Pirttilä T, Nurmikko T, et al. Celiac disease, brain atrophy, and dementia. Neurology 1991;41:372-5.

7 Cooke WT, Smith T. Neurological disorders associated with adult coeliac disease. Brain 1966;89:683-722.

8 Kaplan JG, Pack D, Horoupian D, et al. Distal axonopathy associated with chronic gluten enteropathy: a treatable disorder. Neurology 1988;38:642-5

9 Hadiivassiliou M, Chattopadhyay AK, Davies-Jones GA, et al. Neuromuscular disorder as a presenting feature of coeliac disease. $J$ Neurol Neurosurg Psychiatry 1997;63:770-5.

10 Dyck PJ, Oviatt KF, Lambert EH. Intensive evaluation of referred unclassified neuropathies yields improved diagnosis. Ann Neurol $1981 ; 10: 222-6$

11 McLeod JG. Investigation of peripheral neuropathy. J Neurol Neurosurg Psychiatry 1995;58:274-83.

12 Report of Working Group of European Society of Pediatric Gastroenterology and Nutrition. Revised criteria for diagnosis of coeliac disease. Arch Dis Child 1990;65:909-11.

13 Stålberg E, Nandedkar SD, Sanders DB, et al. Quantitative motor unit potential analysis. J Clin Neurophysiol 1996;13:401-22.

14 Stålberg E, Bischoff C, Falck B. Outliers, a way to detect abnormality in quantitative EMG. Muscle Nerve 1994;17:392-9. 
15 Bischoff C, Stålberg E, Falck B, et al. Reference values of motor unit action potentials obtained with multi- MUAP analysis. Muscle Nerve 1994; 17:842-51.

16 Falck B, Stålberg E, Bischoff C. Sensory nerve conduction studies with surface electrodes. Methods Clin Neurophysiol 1994;5:1-20.

17 Stålberg E, Falck B. Clinical motor nerve conduction studies. Methods Clin Neurophysiol 1993;4:61-80.

18 Haanpää ML, Laippala PA, Nurmikko TJ. Thermal and tactile perception thresholds in acute herpes zoster. Eur J Pain 1999;3:375-86.

19 Waylett-Rendall J. Sensibility evaluation and rehabilitation. Orthop Clin North Am 1988;19:43-56.

20 Hietaharju A, Jääskeläinen S, Kalimo H, et al. Peripheral neuromuscular manifestations in systemic sclerosis (scleroderma). Muscle Nerve $1993 ; 16: 1203-12$
21 Partanen J, Niskanen L, Lehtinen J, et al. Natural history of peripheral neuropathy in patients with non-insulin-dependent diabetes mellitus. $N$ Engl J Med 1995;333:89-94.

22 Holmes G. Neurological and psychiatric complications in coeliac disease. In: Epilepsy and other neurological disorders in coeliac disease. London: John Libbey, 1997:251-64.

23 Muller AF, Donelly MT, Smith CML, et al. Neurological complications of coeliac disease: a rare but continuing problem. Am J Gastroenterol 1996;91:1430-5

24 Bannerii N, Hurwitz L. Neurological manifestations in adult steatorrhea (probable gluten enteropathy). J Neurol Sci 1971;14:125-41.

25 Burk K, Bosch S, Muller CA, et al. Sporadic cerebellar ataxia associated with gluten sensitivity. Brain 2001;124:1013-19.

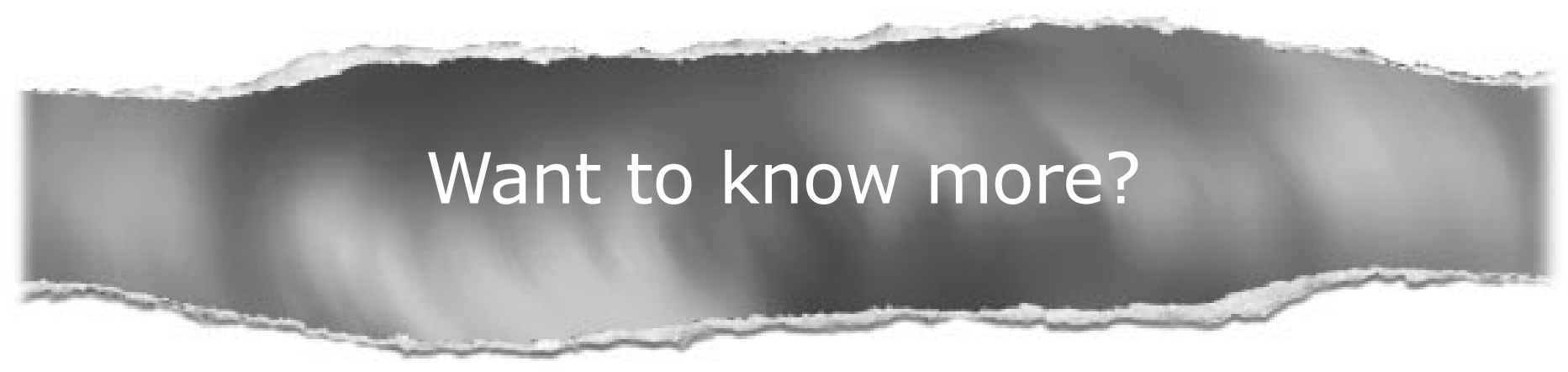

Data supplements

Limited space in printed journals means that interesting data and other material are often edited out of articles; however, limitless cyberspace means that we can include this information online.

Look out for additional tables, references, illustrations.

www.jnnp.com 